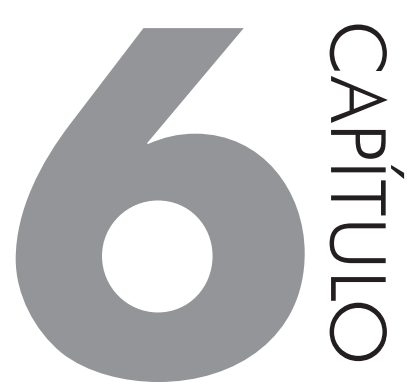

\title{
INTEGRAÇÃO DE METODOLOGIAS ATIVAS DA APRENDIZAGEM NA FORMAÇÃO POLICIAL: GAMIFICAÇÃO E EDUCAÇÃO EM DIREITOS HUMANOS
}

\section{MÁRCIO AZOLINI SCHEFFER, GIOVANI MENDONÇA LUNARDI}

\section{INTRODUÇÃO}

O advento da cultura digital, surgida principalmente com o desenvolvimento de novos equipamentos e aparelhos eletrônicos, e solidificada com a implementação e disponibilidade da internet, possibilitou o progresso das Tecnologias da Informação e Comunicação - TIC - as quais trazem consigo o oferecimento de diversas metodologias e recursos didáticos que podem auxiliar as Academias de Polícia na tarefa de formar e qualificar os agentes operadores de Segurança Pública e constituir uma força policial moderna e eficiente em sua missão de proteger a sociedade e combater o crime, sem deixar de lado os valores norteadores da dignidade humana.

O contexto delineado possibilitou a seguinte pergunta investigativa: a partir da inserção das TICs e suas tecnologias como recursos didáticos pelas Academias de Polícia visando a melhora qualitativa na formação dos agentes de Segurança Pública, o uso da Gamificação como metodologia ativa de aprendizagem é adequada e pode contribuir na docência da temática direitos humanos?

Para responder à questão, optou-se por uma pesquisa de cunho teórico que permitiu reconstruir os argumentos que estruturam os limites e as possibilidades da formação dos agentes de Segurança Pública com a utilização das TICs e suas 
tecnologias, bem como realizou-se um estudo de caso sobre a aplicação dos recursos tecnológicos pela Acadepol/RS. O trabalho metodológico alinhou-se a uma explanação conceitual que permitiu compreender o objeto da pesquisa dentro da literatura analisada.

Primeiramente se realizou um resgate histórico da evolução conceitual dos chamados "direitos humanos", seu papel como agente transformador da atual concepção de como deva ser constituída uma Polícia Cidadã; foram analisados diversos documentos e tratados internacionais e seus similares no âmbito nacional; sendo demonstrada a compatibilidade entre direitos humanos e eficiência policial, uma vez que as habilidades operativas a serem desenvolvidas pelas Academias de Polícia em ações formativas e de qualificação dos operadores de Segurança Pública necessitam estar respaldadas pelos instrumentos legais de proteção e defesa dos direitos humanos, uma vez que direitos humanos e eficiência policial são compatíveis entre si e mutuamente necessários.

Em seguida, fez-se uma explanação das características e desafios da docência nas Academias de Polícia. Realizou-se um comparativo das possibilidades de ganho na qualidade educacional pelos usos das TICs na formação policial, usando-se como parâmetro uma análise do uso destes recursos didáticos na formação profissional.

$\mathrm{Na}$ sequência foi analisado os conteúdos a serem desenvolvidos na formação dos agentes de Segurança Pública que constam em diversos documentos orientativos, entre os quais a Matriz Curricular Nacional para ações formativas dos profissionais da área de segurança pública e o Plano Nacional de Educação em Direitos Humanos; bem como a estrutura do curso "Direitos humanos aplicados à atuação policial" ministrado pela Acadepol/RS e pela Senasp. O capítulo também versa sobre a introdução e aplicação das TICs pela Acadepol/RS, analisando a implementação e uso de diversas ferramentas tecnológicas e seus recursos didáticos.

Por fim, foram apresentadas algumas metodologias ativas da aprendizagem, onde ponderou-se que a Gamificação é um recurso didático apropriado a facilitar a docência dos conteúdos da temática direitos humanos como meio de auxiliar na formação e qualificação dos agentes de Segurança Pública pelas Academias de Polícia.

\section{DIREITOS HUMANOS - CONCEITO E HISTORICIDADE}

A discussão sobre a inclusão e efetivação dos direitos humanos na formação e qualificação dos servidores operadores de Segurança Pública (policiais, bombeiros, guardas municipais, agentes penitenciários e demais servidores de órgãos da justiça e segurança pública) pelas Academias de Polícia - e outras instituições de 
formação e qualificação - ocupa um lugar privilegiado nos debates sobre como deveria ser uma Polícia moderna e cidadã. De uma maneira geral, os direitos humanos estão na ordem do dia no sentido de que estão permanentemente presentes nos discursos de políticos, nas colunas de jornais, nas campanhas de organizações não governamentais e nas políticas públicas de Estados.

Falar em direitos humanos é compreender a um processo histórico que continua em transformação, que evoluiu no decorrer das décadas e segue o rumo de ampliar o leque guarnecido por tais direitos. Justamente por esse processo histórico em evolução, fica extremamente difícil realizar uma conceitualização que abranja toda a dimensão exigida pelos pressupostos basilares de tais direitos. Em seu livro Direitos humanos educação e cidadania Clóvis Gorczevski atentou para essa dificuldade na passagem:

Sempre que nos referimos a Direitos Humanos, todos imediatamente sabem do que estamos falando. Entretanto, a apresentação de um conceito definitivo e absoluto tem sido o grande desafio desde imemoráveis tempos, e ainda sem qualquer êxito. (Gorczevski, 2009, p. 20)

Por sua vez, os autores Alfredo Culleton, Fernanda Frizzo Bragato e Sinara Porto Fajardo, escrevem no livro Curso de direitos humanos a seguinte conceituação:

Aquelas exigências que brotam da própria condição natural da pessoa humana e que, por isso, exigem seu reconhecimento, seu respeito e ainda a sua tutela e promoção da parte de todos, mas especialmente daqueles que estejam instituídos em autoridade. (Culleton, Bragato \& Fajardo, 2009, p. 13)

Os autores seguem na tentativa de uma delimitação conceitual do que sejam os direitos humanos:

Sem dúvidas, o termo direitos humanos é dos mais usados no meio jurídico e político atual, tanto por cientistas, juristas, sociólogos e filósofos que se ocupam do ser humano, do Estado e do Direito como pelo cidadão normal. Por sua função reguladora da legitimidade dos sistemas políticos e dos ordenamentos jurídicos e pela convicção de muitos de que constituem uma garantia para a sua dignidade e são responsáveis por um garantir a sua liberdade e igualdade, a compreensão adequada dos direitos humanos é uma tarefa teórica de alcance prático. (Culleton, Bragato \& Fajardo, 2009, p. 15)

Entretanto, mesmo assim continuam as divergências, como bem colocou Clóvis Gorczevski: 
Assim, cada indivíduo identifica como direitos humanos aqueles valores que, na sua concepção, são vitais para o ser humano. E essa classificação nem sempre coincide entre os indivíduos. O que é vital para um poderá não ser para outrem. Ademais, essa conduta nos leva a uma perigosa e desenfreada multiplicação de "direitos humanos", que vulgariza e desmoraliza a ideia. (Gorczevski, 2009, p. 29)

Outra denominação habitual para os direitos humanos é a de "direitos fundamentais" que também trazem implícitos a convicção popular de que alguns “direitos" são mais direitos dos que os outros e deveriam poder ser exercidos por qualquer ser humano em qualquer lugar ou circunstância.

A primeira concepção do que sejam os direitos humanos surgiu na Idade Média como a imposição de limites ao poder do governante, bem como a de seus agentes, para resguardar alguns direitos dos seres humanos isoladamente considerados. Essa limitação aos poderes do Estado foi proposta na Inglaterra no ano de 1215 no documento "Magna Carta" que reconhecia alguns direitos dos barões com restrição ao poder absoluto do monarca. Em seu livro Direitos humanos $e$ sua proteção, o escritor Hélio Bicudo resgata essa passagem histórica:

Mas é inconteste que a primeira realização concreta dos direitos humanos vem bem depois da Idade Antiga. ... Ainda que de modo incipiente, no período crítico da transição para a Idade Moderna, que foi a chamada Baixa Idade Média, nas comunas e burgos livres da Europa Ocidental. O direito comunal europeu, fundado na liberdade e na igualdade, opunha-se radicalmente à compartimentalização social e às servidões feudais. $\mathrm{O}$ absolutismo real passou a ser contestado, na reação dos barões ingleses que no século XIII impuseram a João Sem Terra o reconhecimento de direitos fundamentais inscritos na chamada Magna Carta e que se aperfeiçoaram nos bills que se lhe seguiram. (Bicudo, 1997, p. 30)

No entanto, foi necessária a passagem de várias gerações para o arcabouço dos direitos humanos começar a ser formatado. Somente no século XVIII, com as Revoluções Francesa e Americana, foram editados os primeiros enunciados sobre o que seriam os direitos humanos. A primeira "declaração" foi à ocorrida na Virgínia/EUA no ano de 1776, que promulgou a igualdade de direitos entre os homens, divisão dos poderes, eleição de representantes, direito de defesa, liberdade de imprensa e liberdade religiosa. Fatos históricos lembrados por Hélio Bicudo:

Depois da Magna Carta de 1215, vieram, bem mais tarde, as declarações dos direitos do homem adotadas nos Estados Unidos às vésperas da declaração da independência em 1776 e na França, a partir da revolução de 1789, manifestando, indiscutivelmente sob esse aspecto, a aparição de uma nova dimensão na vida jurídica em suas relações povo/poder. (Bicudo, 1997, p. 33) 
A segunda "declaração" foi à ocorrida na França em 1789, onde se promulgaram a Declaração dos Direitos do Homem e do Cidadão, que segue como referência ao que sejam os direitos humanos.

O escritor Norberto Bobbio também realiza este resgate histórico sobre a origem dos direitos humanos em uma passagem de seu livro Estado, governo, sociedade:

A última luta pela limitação do poder político foi a que se combateu sobre o terreno dos direitos fundamentais do homem e do cidadão, a começar dos direitos pessoais, já enunciados na Magna Carta de Henrique III [1225] até os vários direitos de liberdade, de religião, de opinião política, de imprensa, de reunião e de associação, que constituem a matéria dos Bill of Rights dos Estados americanos e das Declarações dos direitos do homem e do cidadão emanadas durante a revolução francesa. Seja qual for o fundamento dos direitos do homem - Deus, a natureza, a história, o consenso das pessoas -, são eles considerados como direitos que o homem tem enquanto tal, independentemente de serem postos pelo poder político e que, portanto, o poder político deve não só respeitar, mas também proteger. (Bobbio, 2012, p. 100)

Por sua vez, o professor Nestor Sampaio Penteado Filho apresentou em sua obra Manual de direitos humanos o conceito de direitos humanos como sendo um conjunto de prerrogativas e garantias inerentes ao homem e indissociáveis da condição humana:

Poder-se-ia definir direitos humanos como um conjunto de prerrogativas e garantias inerentes ao homem, cuja finalidade básica é o respeito à sua dignidade, tutelando-o contra os excessos do Estado, estabelecendo um mínimo de condições de vida. São direitos indissociáveis da condição humana. (Penteado Filho, 2006, p. 15)

Os direitos humanos podem ser compreendidos como aqueles direitos constantes em instrumentos internacionais tais como a Declaração Universal dos Direitos Humanos, O pacto internacional sobre os direitos econômicos, sociais e culturais, o pacto internacional sobre os direitos civis e políticos, além de tratados regionais que se dedicam ao tema direitos humanos.

A Declaração Universal dos Direitos Humanos, expedida pela Organização das Nações Unidas (ONU) em 1948, desencadeou um processo de mudanças no comportamento social e a produção de instrumentos e mecanismos internacionais de direitos humanos que foram incorporados ao ordenamento jurídico dos países signatários. Esse processo resultou na base dos atuais sistemas global e regionais de proteção aos direitos humanos. 
A tragédia da Segunda Guerra Mundial resgatou e trouxe um novo patamar à discussão sobre os direitos humanos. O advento da ONU em 1945 e a prioridade de todos os povos do planeta em evitar a eclosão de novas barbáries possibilitou em 1948 a promulgação da Declaração Universal dos Direitos do Homem, realçando a preocupação com o respeito aos direitos humanos em todos os países do mundo, estabelecendo uma mudança de valores na sociedade global, resgatando os princípios da liberdade, da igualdade, da equidade e diversidade do ser humano.

A ONU nasceu do entendimento de que alguns problemas devem ser tratados de forma ampla e necessitam de soluções que envolvam mais de um país ou região. A questão da divulgação, proteção e repreensão a violações dos direitos humanos é um desses problemas, que exigem uma resposta de toda a comunidade internacional, como aponta Clóvis Gorczevski:

Contudo, modernamente, a comunidade internacional não tem aceitado que o problema de violação dos direitos humanos seja uma questão de competência exclusiva dos Estados. A necessidade social e moral de uma defesa realmente efetiva dos direitos humanos, unida a uma crescente abertura da doutrina política e jurídica sobre a matéria, tornaram possível a realização, no século XX, deste grande avanço da humanidade: o reconhecimento e a proteção dos direitos humanos pela ordem internacional. Assim, a tutela desses direitos não é mais uma questão de competência exclusiva dos Estados, mas sim um problema de toda a comunidade internacional. (Gorczevski, 2009, p. 151)

A ONU como uma instituição coletiva de países tem como missão a definição de algumas metas e a solução de algumas questões que envolvem toda a comunidade internacional, entre as quais a divulgação e sustentação dos direitos anunciados na Declaração Universal dos Direitos Humanos, como expressa Culleton, Bragato e Fajardo em outra passagem:

O direito internacional dos direitos humanos, que emergiu desse processo, instituiu, de forma expressa, obrigações aos Estados-Nações, baseadas no pressuposto de que, independente das peculiaridades individuais (nacionalidade, crença, cor, etnia, sexo, orientação sexual, idade, etc.), o ser humano é merecedor de respeito e proteção de determinados bens dos quais é titular. (Culleton, Bragato \& Fajardo, 2009, p. 108)

$\mathrm{Na}$ mesma linha de abordagem sobre a atuação internacional da ONU em sua defesa dos direitos humanos, o professor Costas Douzinas apresenta em sua obra O fim dos direitos humanos a seguinte explanação:

Esta nova visão, de proteção internacional dos direitos humanos, é algo extremamente recente na história da humanidade e inicia com o término da 
segunda guerra mundial. Com a liberdade de imprensa e o desenvolvimento de modernos meios de comunicação, a comunidade internacional tomou conhecimento das barbáries e atrocidades cometidas. Atitudes que envergonham a própria raça humana. Isso veio demonstrar a necessidade de uma proteção mais efetiva aos direitos humanos e que nos leva ao processo de internacionalização desses direitos e resulta na criação de sistemas de proteção internacional, em que é possível à própria responsabilização de um Estado. $\mathrm{O}$ aspecto mais positivo destas ações foi à reformulação do conceito clássico de soberania como um poder ilimitado que não admite restrições ou exceções. (Douzinas, 2009, p. 32)

Estes novos postulados internacionais remetem os direitos humanos como princípios fundamentais que regem os padrões mínimos para o tratamento de cidadãos pelos Estados e Governos e mais particularmente, pelas forças policiais. Neste contexto os profissionais da área da segurança pública devem ter como pano de fundo de suas ações a Declaração Universal dos Direitos Humanos além de outros dispositivos jurídicos de âmbito internacional como o Código de conduta para funcionários responsáveis pela aplicação das leis e o Código de princípios básicos sobre o uso da força e armas de fogo; possibilitando assim que seus atos possam corresponder aos princípios éticos, legais e técnicos na promoção e proteção dos direitos fundamentais do cidadão, como a vida, a integridade física e a dignidade.

No Brasil, esses novos postulados trazidos pela Declaração Universal dos Direitos Humanos percorreu um longo caminho, com tratados, convenções e conferências, até chegar à Constituição Federal de 1988, trazendo inovações no exercício da cidadania e garantindo novos direitos.

\section{EDUCAÇÃO EM DIREITOS HUMANOS NA FORMAÇÃO POLICIAL}

Pela importância que exercem dentro da sociedade, as atribuições dos órgãos de segurança pública e principalmente a atividade policial deve ter suas funções muito bem delimitadas, uma vez que dependendo da maneira como forem exercidas essas atividades de controle social, elas confirmam ou negam o Estado Democrático de Direito, além de que esses órgãos também são os garantidores de que outros órgãos não executem violações aos direitos humanos. Esse é o pensamento que o pesquisador Herman Goldstein apresenta em sua obra Policiando uma sociedade livre:

A polícia não está apenas obrigada a exercer sua limitada autoridade em conformidade com a Constituição e, por meios legais, aplicar suas restrições: também está obrigada a observar que outros não infrinjam as liberdades garantidas constitucionalmente. Essas exigências introduzem na função 
policial a dimensão única que torna o policiamento neste país um ofício seríssimo. (Goldstein, 2003, p. 28)

O pesquisador Paulo Vieira Aveline apresenta em seu artigo Segurança pública como direito fundamental uma referência à importância do órgão de segurança pública e a transformação sofrida pela Polícia na execução de sua função fim que é a segurança dos cidadãos:

Dentre as profissões públicas pode-se dizer que a polícia é uma das que possui maior responsabilidade em relação à imagem do Estado. É necessário que os agentes públicos de segurança resgatem os anos perdidos de autoritarismo e distanciamento da sociedade brasileira. A história da origem policial no Brasil explica o porquê de seus traços de violência. Tendo em vista esse histórico, cada policial ao entrar na corporação deve estar consciente de que a polícia não é mais a mesma, agora mais que nunca; deve-se fortalecer o sentido de fazer de sua missão um ato nobre. Policiais devem respeitar os direitos humanos no desenvolvimento de suas atividades profissionais. Em direitos humanos, o requisito de respeito a esses direitos afeta diretamente o modo como a polícia desempenha todas as suas funções. (Aveline, 2009, p. 28)

Seguindo estes novos preceitos internacionais de defesa e difusão dos direitos humanos, o Governo Federal, por meio da Secretaria Especial dos Direito Humanos, elaborou e lançou no ano de 2007 o Plano Nacional de Educação em Direitos Humanos - PNEDH - ação conjunta entre os Ministérios da Educação e da Justiça com a Unesco - que estabeleceu parâmetros para a capacitação dos profissionais encarregados da segurança pública no âmbito de todo o território nacional:

A capacitação de profissionais dos sistemas de justiça e segurança é, portanto, estratégica para a consolidação da democracia. Esses sistemas, orientados pela perspectiva da promoção e defesa dos direitos humanos, requerem qualificações diferenciadas, considerando as especificidades das categorias profissionais envolvidas. Ademais, devem ter por base uma legislação processual moderna, ágil e cidadã. (Brasil, 2007, p. 48)

Essas novas perspectivas sociais das atribuições dos órgãos de segurança pública - voltadas agora para uma segurança cidadã que respeite os limites de atuação dos parâmetros internacionais - trazem uma nova concepção das Polícia como organizações de servidores corretos e respeitadores dos direitos dos cidadãos, com particular reforço ao cuidado dos critérios de seleção, preparação e formação dos agentes policiais pelas Academias de Polícia.

O pesquisador Benedito Domingos Mariano faz, em sua obra Polícia: desafio da democracia brasileira, apontamentos sobre como os servidores da segurança pública se veem diante dos novos pressupostos dos direitos humanos: 
Diante desse atual quadro da Instituição, perguntamos: O que faz a Polícia Civil para que os Direitos Humanos sejam respeitados e aplicados por seus servidores no exercício de suas funções? É essa questão que será respondida nas páginas seguintes. Mas desde já podemos traçar um quadro diferente daquele de 20 (vinte) anos atrás, onde os policiais não tinham consciência da expressão "Direitos Humanos" ou sequer sabiam de sua existência. Atualmente os funcionários da Polícia Civil já conhecem a expressão e chegam a associar o termo "proteção" a ela, embora desconheçam seus mecanismos de funcionamento. (Mariano, 2002, p. 14)

O Brasil se efetivou como um país democrático de direito após a promulgação da Constituição Federal de 1988, também chamada de "Constituição Cidadã" por contar com garantias e direitos fundamentais que reforçam a ideia de um país livre e pautado na valorização do ser humano. Com essa nova concepção de Estado, o Plano Nacional de Educação em Direitos Humanos estabeleceu que os órgãos encarregados da segurança pública devam promover a difusão e a garantia dos direitos humanos, como pode ser constatado na passagem:

Para a consolidação desse modelo de Estado é fundamental a existência e o funcionamento de sistemas de justiça e segurança que promovam os direitos humanos e ampliem os espaços da cidadania. No direito constitucional, a segurança pública, enquanto direito de todos os cidadãos brasileiros, somente será efetivamente assegurada com a proteção e a promoção dos direitos humanos. A persistente e alarmante violência institucional, a exemplo da tortura e do abuso de autoridade, corrói a integridade do sistema de justiça e segurança pública. (Brasil, 2007, p. 47)

O Plano Nacional de Educação em Direitos Humanos também faz uma referência à Constituição Federal ao estabelecer os objetivos dos órgãos encarregados da segurança pública como "dever do Estado, direito e responsabilidade de todos":

No que se refere à função específica da segurança, a Constituição de 1988 afirma que a segurança pública como "dever do Estado, direito e responsabilidade de todos, é exercida para a preservação da ordem pública e da incolumidade das pessoas e do patrimônio" (art. 144). Define como princípios para o exercício do direito à justiça, o respeito da lei acima das vontades individuais, o respeito à dignidade contra todas as formas de tratamento desumano e degradante, a liberdade de culto, a inviolabilidade da intimidade das pessoas, o asilo, o sigilo da correspondência e comunicações, a liberdade de reunião e associação e o acesso à justiça (art. $5^{\circ}$ ). (Brasil, 2007, p. 47)

Diante dessa nova demanda social surgida na valorização da pessoa humana, cabe às Academias de Polícia prestarem uma formação policial qualificada 
para a execução de suas funções de manterem a ordem pública e a defesa das instituições democráticas com observância aos princípios basilares de defesa e promoção dos direitos humanos. Nos parágrafos a seguir, serão apresentadas algumas particularidades sobre a docência nas Academias de Polícia e de como os recursos tecnológicos podem auxiliar na difícil tarefa de transmitir conhecimentos que vão além de conteúdos que expressam, não somente questões jurídicas e operacionais, mas também, valores sociais e normas de conduta moral.

\section{DESAFIOS DA FORMAÇÃO POLICIAL PELAS ACADEMIAS DE POLÍCIA PARA CONSTRUIR UMA POLÍCIA CIDADÃ}

A ideia central desta exposição é demonstrar a importância e desafios da docência da temática direitos humanos na formação policial, uma vez que espera-se um padrão de conduta dos agentes operadores de segurança pública que tenha como balizas os valores resguardados pelo rol da dignidade da pessoa humana e dos mais variados direitos (civis, políticos, econômicos, sociais, culturais e ambientais), para isso esses profissionais necessitam estar conscientes e críticos de sua realidade e atribuições.

Os debates sobre a formação de uma nova Polícia ou uma Polícia Cidadã, bem como o reconhecimento dos direitos humanos e o estabelecimento da cidadania se iniciaram ao final da Ditadura Militar e alcançaram grande relevância a partir da década de 1990 por meio de ações governamentais e de proposições da sociedade civil organizada no campo das políticas públicas, as quais almejavam o fortalecimento da democracia. Uma concepção contemporânea de direitos humanos incorpora os conceitos de cidadania democrática, a qual, por sua vez, denota inspiração em valores humanistas e embasada nos princípios da liberdade, da igualdade, da equidade e da diversidade.

Esse padrão de conduta almejado pela sociedade será proporcionado pelo desenvolvimento das capacidades pessoais dos agentes policiais e serão desenvolvidas dentro de um processo de aprendizagem que se define, na sociedade moderna, por uma educação generalizada e uma formação qualificada.

Os novos anseios da sociedade por uma Polícia Cidadã esperam que a formação policial ofertada pelas Academias de Polícia seja exercida, nas suas mais variadas peculiaridades, pela busca da excelência na qualidade do desempenho profissional, sobre os limites de atuação, a capacidade de empatia para reconhecer e conviver com todos os valores sociais e culturais; assim como, contribuir para o aumento da difusão e compreensão de mundo estabelecido sobre os ditames da democracia.

Para que ocorra essa qualificação na formação dos operadores de segurança pública e futuros policiais, as Academias de Polícia precisam estar sintonizadas 
com o que a sociedade espera desses profissionais. É um desafio para as Academias de Polícia realizarem essa formação qualificada, a qual deve desenvolver uma série de habilidades necessárias a realização da atividade policial, que vão desde conhecimentos jurídicos das mais diversas áreas aos específicos ao desempenho das atividades policiais, passando pela noção de primeiros socorros e defesa pessoal, além do preparo físico necessário a função.

As peculiaridades da formação policial foram objeto de um estudo realizado pela Secretaria Nacional de Segurança Pública (Senasp) em convênio com diversos organismos internacionais como ONU e Cruz Vermelha, entre tantos outros, que resultou no documento denominado Matriz Curricular Nacional para ações formativas dos profissionais da área de segurança pública, que caracteriza-se por ser um referencial teórico-metodológico para orientar as ações referentes a formação e qualificação dos profissionais da área de segurança pública pelas Academias de Polícia e demais instituições.

Entre estas diretrizes estabelecidas pela Matriz Curricular Nacional, consta a valorização da temática dos direitos humanos na formação policial, como pode ser constatado na passagem:

A questão dos direitos humanos aplicados à ação dos profissionais de segurança pública está cercada de mitos e equívocos que atravessam o imaginário social e, particularmente, a cultura tradicional dos órgãos mantenedores da segurança pública. Apesar dos avanços, tem prevalecido uma visão de antagonismo entre os dois. O profissional de segurança pública eficiente e profissionalizado em padrões de excelência precisa estar eticamente comprometido com os direitos humanos, como referência primordial de sua ação técnica, dando, assim, uma resposta aos anseios de justiça e legalidade do sistema democrático, sem prejuízo da eficiência e da força na prevenção e repressão do crime. Direitos humanos e atividade do profissional de segurança pública ainda soam como polos antagônicos no imaginário público. Tal situação se deve a uma série de fatores históricos e culturais que a cada dia vêm sendo superados pela consciência cívica da população brasileira, pelos esforços dos governantes sérios e pela dedicação de dirigentes públicos comprometidos com a ética e a democracia. Assim sendo, é necessário que o profissional de segurança pública entenda que a proteção dos direitos fundamentais da pessoa humana é uma obrigação do Estado e do governo em favor da sociedade e que o profissional da área de segurança pública é um dos agentes da promoção e proteção desses direitos. (Brasil, 2014, p. 113)

Diante de tamanha responsabilidade, para cumprir seu papel, o ensino nas Academias de Polícia necessita de docentes com características diferenciadas, cuja experiência profissional venha a contribuir para o melhor desempenho da prática 
docente na transmissão de seus conhecimentos. Assim, uma formação de excelência dos futuros policiais ou reciclagem dos mais antigos, exige que o instrutor ou professor tenha, além dos conhecimentos inerentes à didática, experiência e atuação na área.

Entretanto, um dos grandes desafios a serem superados pelas Academias de Polícia é a comumente falta de habilidades didáticas de seus professores e instrutores, que por serem na maioria das vezes policiais de carreira e sem muita intimidade com os quesitos pedagógicos, acreditam que a formação policial deva ser concebida somente como um modelo de transmissão de conhecimentos que futuramente seriam utilizados nas práticas dos futuros profissionais.

As pesquisadoras Heloisa Maria Gomes e Hiloko Ogihara Martins realizaram um estudo sobre a docência na educação profissionalizante que resultou na obra $A$ ação docente na educação profissional, onde expressam a constatação da carência de formação pedagógica dos docentes que atuam na educação profissional, como mostrado na passagem do livro:

Em geral, os professores da educação profissional são selecionados principalmente por seu desempenho técnico, pela especificidade e pela experiência no mercado de trabalho. A maioria desses professores não apresenta formação pedagógica, nem mesmo experiência docente, o que tem levado algumas instituições de ensino a adotarem programas de formação continuada, garantindo a formação específica para o magistério. Tomamos aqui, como exemplo, o Programa de Desenvolvimento Educacional (PDE) do Senac São Paulo, que tem como objetivo desenvolver pedagogicamente técnicos, docentes e coordenadores que atuam na instituição como funcionários e como docentes convidados dos diversos cursos técnicos, de especialização e de aperfeiçoamento profissional. (Gomes \& Martins, 2013, p. 156)

As Academias de Polícia, na grande maioria das vezes optam para que a docência seja exercida por policiais de carreira, uma vez que já possuem conhecimentos sistematizados da sua área de atuação, e que pela prática, poderiam responder prontamente diante das questões pertinentes aos problemas da profissão. Essa prática se origina na premissa de que o policial desenvolve suas competências essencialmente na prática e a partir da prática, bem como alicerça-se no pressuposto de que a teoria não alcança os imediatos desafios que a prática implica; assim, se os instrutores ou professores que nunca tiveram nenhuma experiência na atividade policial, não teriam condições de ultrapassarem e nem questionarem o conteúdo que estão ministrando.

São raros os policiais que atuam como docentes nas Academias de Polícia e que tenham formação nas áreas pedagógicas ou de licenciaturas; fator que poderia enriquecer muito a formação policial uma vez que suas competências seriam 
extraídas tanto de seus conhecimentos acadêmicos quanto dos saberes vindos da experiência e da ação, do enfrentamento de situações em seu cotidiano no desempenho de suas funções. É um posicionamento equivocado supor que a falta de didática possa ser substituída pelos conhecimentos práticos e estudos de casos. De posse dessas bagagens pessoais oportunizadas por formação profissional na área de ensino, os instrutores ou professores teriam uma grande facilidade de estabelecerem relações efetivas entre teoria e prática, atendendo a questionamentos dos alunos ou provocando neles novas necessidades de busca e de pesquisa.

É necessário ressaltar que a formação policial se insere em um mundo em constante mudança e diante das novas concepções de sociedade. Agregadas a valorização dos direitos humanos, a qualificação policial tem de ser mais do que uma mera assimilação certificada de saberes, muito mais do que preparar ou treinar pessoas para a realização de determinadas tarefas ou utilização de instrumentos ou equipamentos. As Academias de Polícia precisam assumir o papel de formar policiais aptos a exercerem suas atividades diante das complexidades e desafios que a atividade pressupõe.

Os desafios são preparar profissionais qualificados e cidadãos conscientes, que possam analisar criticamente o excesso de informações e as mudanças sociais, a fim de lidar com as inovações e as transformações sucessivas dos conhecimentos em todas as áreas e demandas que a profissão exigem. Para cumprirem essa tarefa, as Academias de Polícia precisam estimular que seu quadro docente adquira saberes e conhecimentos das áreas pedagógicas e didáticas. A docência deve ser compreendida como um processo socializador que facilita a compreensão de determinadas situações e permita o desenvolvimento de habilidades que devem ser dominadas pelos futuros policiais para a realização de suas atribuições de forma qualificada e competente. Assim, as estratégias para a superação dos novos desafios deverão ser construídas em sintonia com a redefinição de novas diretrizes para a formação de uma Polícia Cidadã capacitada a defender e promover os direitos humanos em toda a sociedade.

A prática docente das Academias precisa se atualizar e se reinventar, necessita reconhecer e começar a utilizar os novos recursos tecnológicos como ferramentas facilitadoras das ações de ensinar e aprender. E como toda ferramenta, deve ser utilizada e não guardada para ser usada em um momento futuro. É preciso romper a tradição da apresentação oral e textual que seguem sempre uma ordem sequencial, como apontou o escritor Luz Carlos Pais ao fazer uma pesquisa sobre a introdução das tecnologias da informática na educação escolar, explanadas em sua obra Educação Escolar e as Tecnologias da Informática:

A forma linear de apresentação textual do livro, concebida sempre em numa ordem sequencial e hierarquizada, não é suficiente para explorar todas as 
alternativas de aprendizagem que os dispositivos computacionais oferecem. É preciso priorizar programas criados a partir de uma dinâmica hipertextual, caracterizada pela existência de várias opções representadas por vários nós e links, sinalizando caminhos múltiplos que o usuário deve escolher por sua livre iniciativa e autonomia. Essas habilidades, propiciadas e exigidas pelo uso dos computadores, mostram o direcionamento da redefinição de novos objetivos a serem alcançados na prática educativa. Não podemos nem mesmo insinuar que no hipertexto não tenha nenhuma linearidade, pois na construção do seu algoritmo básico o seu criador utiliza um raciocínio fundamentado numa lógica sequencial. Assim, tais programas são inovadores por conciliarem uma lógica sequencial com uma aparente ausência de sequência a ser seguida pelo usuário. (Carlos Pais, 2010, p. 17)

A cultura digital surge na metade do século passado, fazendo surgirem novos paradigmas em busca de explicações para os mais diversos fenômenos, trazendo novas visões de mundo para as ciências e principalmente para a educação. As Academias de Polícia e seus professores não podem mais ficar à margem deste movimento global de influência das mídias e da tecnologia; estas instituições de formação e qualificação devem se tornar um espaço de ressignificação da informação e do conhecimento. Nos espaços escolares onde já existem experiência de uso das Tecnologias de Informação e Comunicação - TICs - como recursos didáticos e de aprendizagem, os professores sentem os seus alunos mais receptivos à proposta de usar uma ferramenta lúdica para aprender. Esse movimento de introdução das TICs na educação vem pautada pela ideia de mudança e de melhora na qualidade educacional e, com isso, na formação humana. Diante disso, as Academias de Polícia não podem permanecerem a margem desse movimento, mas sim introduzirem esses novos recursos tecnológicos como ferramentas ao auxílio da prática docente.

O desenvolvimento das tecnologias digitais da informação e da comunicação nas últimas duas décadas trouxe novas possibilidades e desafios a todas as áreas e níveis da atividade docente em geral e não poderia ser diferente nas Academias de Polícia, que nada mais são do que estabelecimentos de ensino. Não há dúvidas de que os avanços tecnológicos interferem na vida das pessoas e em todas as atividades profissionais, basta lembrar que há menos de vinte anos atrás eram poucas as pessoas que possuíam um aparelho de telefone celular, acesso à internet e outros tantos mecanismos que podem facilitar a vida e influenciam grandemente na forma como interagimos com os outros.

Os desafios enfrentados pelas Academias de Polícia frente as novas possibilidades ofertadas pelas TICs e suas tecnologias passam pelos mesmos paradigmas enfrentados pelo ensino tradicional, que necessita superar o sistema centrado apenas na exposição verbal do professor para um modelo de ensino mais colaborativo e com maior intensidade de mediações. Entretanto, mesmo tendo a tecnologia 
a seu favor, o corpo docente precisa compreender e explorar corretamente os recursos pedagógicos de que dispõe como meios e não como fins em si mesmos, possibilitando o desenvolvimento de competências que estejam em sintonia com a realidade que será enfrentada na execução das atividades profissionais.

Diante dessa nova perspectiva, as Academias de Polícia necessitam acompanhar as mudanças tecnológicas e seus instrutores ou professores precisam estar constantemente inovando, no sentido de tornar o aprendizado cada vez mais significativo e, consequentemente, proporcionar ao futuro policial oportunidades de refletir sobre o seu próprio agir. Os novos recursos tecnológicos oportunizam um aprendizado interativo e intersubjetivo, mas também impões uma adaptação dos métodos tradicionais de ensinar e de aprender, além de uma readaptação dos professores para o uso adequado dessas novas ferramentas tecnológicas.

\subsection{Conteúdo dos cursos com a temática direitos humanos na formação e qualificação dos profissionais operadores de segurança pública}

O conteúdo da temática direitos humanos apresenta veemência na formação policial e dos demais servidores que atuaram como operadores de Segurança Pública e possui a maior incidência nas aulas da disciplina "Filosofia dos Direitos Humanos Aplicados à Atuação Policial”, tanto o ministrado pela Acadepol/RS (presencial) como pela Senasp (Ead). Os dois cursos seguem o estabelecido na Matriz Curricular Nacional e balizado pelo Plano Nacional de Educação em Direitos Humanos o qual estabelece no capítulo IV Educação dos Profissionais dos Sistemas de Justiça e Segurança que "os direitos humanos são condições indispensáveis para a implementação da justiça e da segurança pública em uma sociedade democrática”. (Brasil, 2009, p. 47)

Por sua vez, a Matriz Curricular Nacional propõe uma valorização da capacidade de utilização crítica e criativa dos conhecimentos, e não o simples acúmulo de informações em suas diretrizes pedagógicas e na proposta metodológica que possibilitam às instituições de ensino de segurança pública - Academias e/ou Escolas - a planejarem as ações formativas (inicial e continuada) para que os profissionais da área de segurança pública possam, de maneira autônoma e responsável, refletir e agir criticamente em situações complexas e rotineiras de trabalho, como pode ser conferido na passagem:

As ações formativas de segurança pública, planejadas com base na Matriz, têm como objetivo geral favorecer a compreensão do exercício da atividade de segurança pública como prática da cidadania, da participação profissional, social e política num Estado Democrático de Direito, estimulando a adoção de atitudes de justiça, cooperação, respeito à Lei, promoção humana e repúdio a qualquer forma de intolerância. (Brasil, 2014, p. 41) 
A Matriz Curricular Nacional propõe que os agentes operadores de segurança pública devam desenvolver em sua formação diversas competências, que foram selecionadas e classificadas em três grandes grupos, tomando como base às dimensões do conhecimento: cognitivas, operativas e atitudinais (BRASIL, 2014, p. 20). A seguir um resumo das habilidades e competências a serem dominadas pelos agentes operadores de segurança pública (Figura 1):

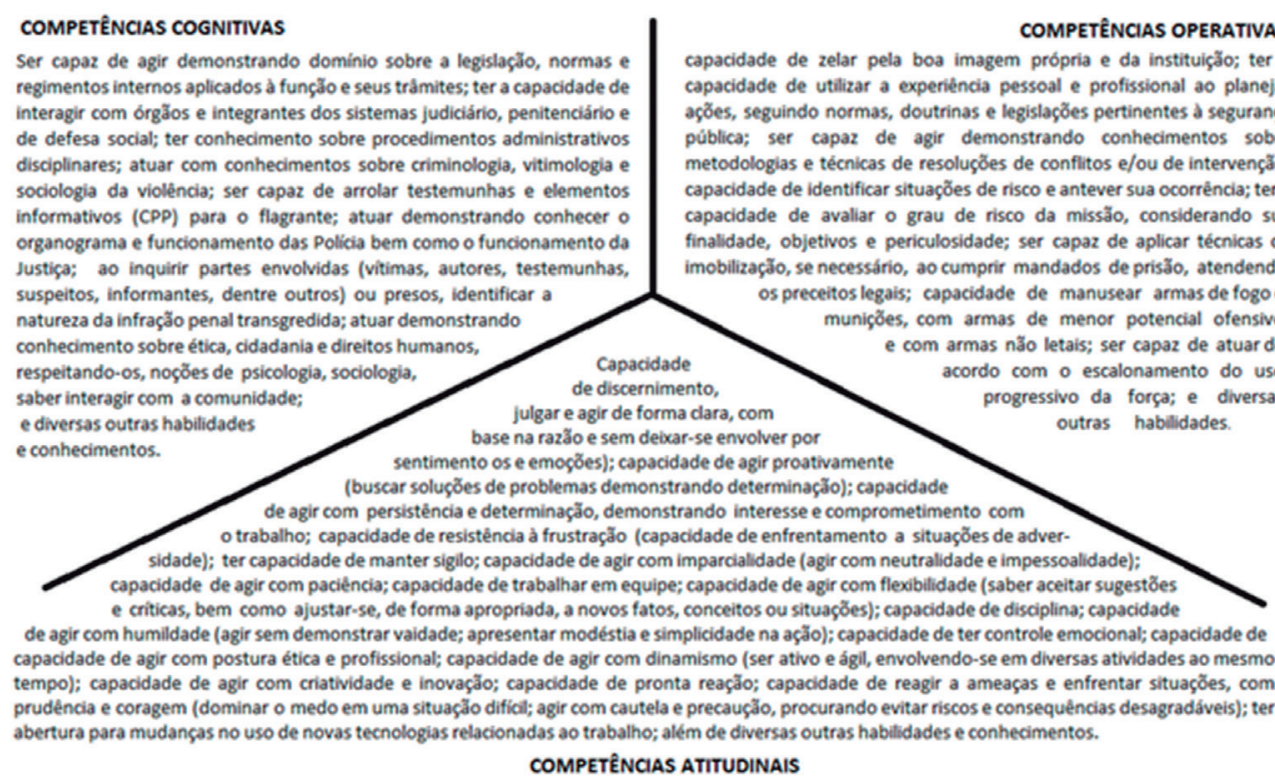

Ser capaz de agir demonstrando domínio sobre a legislaçäo, normas e regimentos internos aplicados à função e seus tràmites; ter a capacidade de interagir com órgãos e integrantes dos sistemas judiciário, penitenciário e de defesa social; ter conhecimento sobre procedimentos administrativos disciplinares; atuar com conhecimentos sobre criminologia, vitimologia e sociologia da violência; ser capaz de arrolar testemunhas e elementos informativos (CPP) para o flagrante; atuar demonstrando conhecer o organograma e funcionamento das Policia bem como o funcionamento da Justica; ao inquirir partes envolvidas (vitimas, autores, testemunhas, suspeitos, informantes, dentre outros) ou presos, identificar a natureza da infração penal transgredida; atuar demonstrando conhecimento sobre ética, cidadania e direitos humanos, respeitando-os, noçōes de psicologia, sociologia, saber interagir com a comunidade; e diversas outras habilidades e conhecimentos.

Capacidade de discernimento, julgar e agir de forma clara, com base na razăo e sem deixar-se envolver por sentimento os e emocões); capacidade de agir proativamente (buscar soluçōes de problemas demonstrando determinação); capacidade de agir com persistência e determinação, demonstrando interesse e comprometimento com o trabalho; capacidade de resistência à frustração (capacidade de enfrentamento a situações de adversidade); ter capacidade de manter sigilo; capacidade de agir com imparcialidade (agir com neutralidade e impessoalidade) capacidade de agir com paciência; capacidade de trabalhar em equipe; capacidade de agir com flecibilidade (saber aceitar sugestões e criticas, bem como ajustar-se, de forma apropriada, a novos fatos, conceitos ou situaçöes); capacidade de disciplina; capacidade de agir com humildade (agir sem demonstrar vaidade; apresentar modéstia e simplicidade na açăo); capacidade de ter controle emocional; capacidade de capacidade de agir com postura ética e profissional; capacidade de agir com dinamismo (ser ativo e ágil, envolvendo-se em diversas atividades ao mesmo tempo); capacidade de agir com criatividade e inovação; capacidade de pronta reação; capacidade de reagir a ameaças e enfrentar situaçōes, com prudência e coragem (dominar o medo em uma situaşّ̋o dificil; agir com cautela e precauçăo, procurando evitar riscos e consequências desagradáveis); ter abertura para mudanças no uso de novas tecnologias relacionadas ao trabalho; alem de diversas outras habilidades e conhecimentos.

COMPETENCIAS ATITUDINAIS

Figura 1 Habilidades e competências a serem dominadas pelos agentes operadores de segurança pública.

Fonte: Elaborado por Márcio Azolini Scheffer.

A Senasp oferece aos agentes de segurança pública diversos cursos de qualificação e atualização na modalidade Ead, nos quais não há pré-requisito de escolaridade. Também são oferecidos alguns cursos na modalidade presencial e semipresencial em parceria com algumas instituições de ensino superior, nestes casos, os cursos são de pós-graduação a título de especialização e/ou mestrado.

A temática dos direitos humanos permeia a totalidade dos cursos oferecidos pela Senasp, entretanto, o específico sobre o assunto é o curso Filosofia dos direitos humanos aplicados à atuação policial, ministrado na modalidade Ead e com uma carga horária de 40 horas.

A criação e instrução do curso Filosofia dos direitos humanos aplicados à atuação policial propõe-se a fornecer aos agentes operadores da Segurança Pública os aportes jurídicos, filosóficos e conceituais referentes aos direitos humanos 
no âmbito do direito internacional e do direito brasileiro, relacionando-os com a atividade e conduta esperada de um policial numa democracia, prevenindo a ocorrência de crimes, investigando os já ocorridos, mantendo e preservando a ordem pública de modo que os direitos e obrigações de todos em contato com os encarregados pela aplicação da lei sejam observados.

\section{A GAMIFICAÇÃO DE CONTEÚDOS COMO RECURSO DIDÁTICO DE MOTIVAÇÃO E FACILITADOR DA APRENDIZAGEM}

A instrução de conteúdos voltados à temática dos direitos humanos na formação e qualificação policial - e dos demais operadores de Segurança Pública necessita transcender a mera exposição de textos ou palestras sobre o assunto. Como o conteúdo pressupõe o domínio de diversos saberes e normas de conduta frente a determinadas situações, não basta ao policial ter o conhecimento de leis e códigos, é necessário que esse profissional tenha compreensão de suas atribuições e limites de atuação. É uma situação rotineira das Academias de Polícia desprenderem maiores esforços na formação de habilidades ligadas diretamente a atividade fim da corporação, como por exemplo a investigação criminal para as Polícia Civis, de ronda e patrulhamento pelas Polícia Militares, sem contar com o grande número de horas dedicadas a instrução de tiro; deixando para um segundo plano os assuntos e conteúdos ligados a questão dos direitos humanos. Todo professor/instrutor conhece o desafio de estimular e manter a motivação do aluno e da dificuldade de encontrar métodos confiáveis e válidos para isto; além de que manter o aluno motivado é tão difícil quanto motivá-lo. Este capítulo propõe-se a discutir as contribuições da Gamificação de conteúdos como recurso didático de motivação e facilitador da aprendizagem.

Os métodos tradicionais, que privilegiam a transmissão de informações pelos professores, faziam sentido quando o acesso à informação era difícil e restrito. Com a Internet e a divulgação aberta de muitos cursos e materiais, pode-se aprender em qualquer lugar, a qualquer hora e com muitas pessoas diferentes. Por isso a educação formal está se reinventando, uma vez que não pode mais se dar somente no espaço físico da sala de aula, precisando estar presente nos múltiplos espaços do cotidiano, que incluem os digitais. O professor precisa seguir comunicando-se face a face com os alunos, mas também digitalmente, com as tecnologias móveis, equilibrando a interação com todos e com cada um.

Essa mescla, entre sala de aula e ambientes virtuais é fundamental para abrir a sala de aula para o mundo atual e para trazer esse novo mundo digital para dentro da sala de aula. Um dos objetivos dessa interligação é a de prever processos de comunicação mais planejados, organizados e formais com outros mais abertos, como os que acontecem nas redes sociais, onde há uma linguagem 
mais familiar, uma espontaneidade maior, uma fluência de imagens, ideias e vídeos constantes.

Atualmente existem inúmeras novas formas de produzir e desenvolver conteúdos diferenciados para o ambiente de aprendizagem que surgiram com a evolução das tecnologias digitais para auxiliar à educação. Aliadas as novas contribuições da cultura digital, existem diversas metodologias que possibilitam novas maneiras de ensinar e sua criação tem base nos paradigmas de orientação ao objeto das ciências da computação, tecnologia da informação, sistemas tutoriais inteligentes, e psicologia educacional. Nesse contexto as denominadas "metodologias ativas da aprendizagem" surgem como proposta para focar o processo de ensinar e aprender na busca da participação ativa de todos os envolvidos, centrados na realidade em que estão inseridos. Existem diversas metodologias ativas da aprendizagem, como por exemplo:

- Aprendizagem baseada em problemas: essa metodologia intitulada Problem Based Learning (PBL) ou Aprendizagem Baseada em Problemas ou ABP que foi bastante aceita no meio acadêmico e, na atualidade é reconhecida como o que há de mais moderno no ensino superior é um método educativo surgido na Universidade de Maastricht, e com maior implementação na Universidade McMaster. Estabelece uma estratégia pedagógica centrada no aluno, onde se procura que este aprenda por si próprio. $\mathrm{O}$ delineamento é elementar. Os docentes expõem um caso para estudo aos estudantes, que estabelecidos em grupos de trabalho, identificam o problema, investigam, debatem, interpretam e produzem possíveis justificações e soluções ou resoluções, ou recomendações. A ABP tem como base de inspiração "os princípios da escola ativa, do método científico, de um ensino integrado e integrador dos conteúdos, dos ciclos de estudo e das diferentes áreas envolvidas, em que os alunos aprendem a aprender e se preparam para resolver problemas relativos à sua futura profissão".

- Sala de aula invertida: essa metodologia da sala de aula invertida ou flipped classroom é um sistema ativo que ressignifica o papel do aluno, do professor e da aprendizagem. Esta proposta de aprendizagem propõe que o aluno antes da aula estude sobre uma temática específica, vindo desta maneira mais preparado, com questionamentos e inquietações que serão o ponto de partida para as discussões na sala de aula. A aula passa a ser dialógica e interativa, invertendo assim a transmissão de conhecimento usada no ensino tradicional, onde o aluno, como um ser passivo, escuta o professor, faz atividades e estuda em casa para a prova.

- Educação híbrida: a metodologia do "ensino híbrido" envolve a utilização das tecnologias com foco na personalização das ações de ensino e de aprendizagem, apresentando aos educadores formas de integrar tecnolo- 
gias digitais ao currículo escolar. Além disso, essa abordagem apresenta práticas que integram o ambiente online e presencial, buscando que os alunos aprendam mais e melhor.

- Moocs: é a sigla em inglês para Massive Open Online Courses, ou seja, Cursos Online Abertos e Massivos; trata-se, portanto, de cursos online, totalmente gratuitos, que objetivam a participação em larga escala através da Internet. A ideia principal é procurar manter a mesma qualidade de um curso presencial de nível superior, mas usando a Internet para atingir um número tão grande de pessoas que o custo por aluno se torna irrisório.

- Gamificação: o desenvolvimento da ciência da Gamificação originou-se de uma constatação óbvia e historicamente comprovada: seres humanos são atraídos por jogos. Ao longo dos séculos, praticamente todos os povos tiveram jogos como pilares importantes de suas sociedades. Hoje, 3 bilhões de horas são dispensadas coletivamente por semana em jogos online apenas, o que reforça não só a importância social, mas também econômica dos games na vida de centenas de milhões de pessoas. A Gamificação se apropria dos mecanismos de engajamento utilizados nos jogos para resolver problemas práticos. Ainda que em alguns casos apareça como algo divertido, o objetivo final da Gamificação não é o entretenimento, mas sim despertar o engajamento de um determinado público com uma causa específica.

O termo "Gamificação" foi cunhado pela primeira vez pelo pesquisador britânico Nick Pelling, que era programador de computadores e criava softwares e jogos. O conceito de Gamificação é muito recente, a sua definição ainda se encontra um tanto nebulosa que por vezes podem ser conflitantes ou complementares; algumas já foram cunhadas e, como se trata de um conceito que pode ser empregado em diversas áreas, as definições recebidas são influenciadas pela área na qual ela foi elaborada. De uma maneira geral, a Gamificação consiste em utilizar a mecânica dos jogos em atividades que não estão dentro do contexto dos jogos, mas com a intenção de promover a motivação e o comportamento do indivíduo. A pesquisadora e professora Lynn Rosalina Gama Alves, junto com seus colaboradores Marcelle Rose da Silva Minho e Marcelo Vera Cruz Diniz escreveram o artigo Gamificação: diálogos com a educação onde apresentam alguns exemplos de emprego dos recursos da Gamificação:

Empresas já utilizavam as lógicas da recompensa e da pontuação para treinamento de seus funcionários, programas de televisão mantinham ou aumentavam o número de espectadores utilizando essas técnicas, empresas de vendas de produtos e propaganda utilizavam para aumentar a sua malha de vendedores. (Alves, Minho \& Diniz, 2014, p. 77) 
No artigo Gamificação e objetos de aprendizagem os autores Márcia Maria Alves e Oscar Teixeira fazem uma análise de como os elementos de construção de games podem auxiliar na aprendizagem:

Uma dessas estratégias é a Gamificação. A palavra Gamificação vem sendo utilizada para denominar a situação em que se pretende adotar elementos de jogos para uso em outros contextos e atividades que não são jogos puros e completos. No âmbito educacional objetos gamificados atuariam como objetos de aprendizagem estruturados como jogos ou que adotam algumas características destes. Para isso, se faz necessário remodelar o design destes objetos, adotando alguns padrões e conceitos dos jogos assim como algumas diretrizes para desenvolvimento das atividades sob esta ótica. (Alves \& Teixeira, 2013, p. 131)

A proposta da Gamificação tem como base a ação de se pensar os processos de aprendizagem como em um jogo, utilizando as sistemáticas e mecânicas do ato de jogar em um contexto de sala de aula; entretanto, isso não significa, necessariamente, a participação em um jogo, mas a utilização dos elementos mais eficientes - como dinâmicas e estética - para reproduzir os mesmos benefícios alcançados com o ato de jogar, uma vez que a Gamificação explora os níveis de engajamento do indivíduo para a resolução de problemas.

Diversas teorias contemporâneas sobre a aprendizagem convergem em apontar que as pessoas aprendem com maior rapidez e eficiência a partir de suas experiências anteriores. Elas armazenam estas experiências na memória e as utilizam para gerar simulações que facilitam na formulação de hipóteses para a resolução de problemas futuros em diferentes contextos.

A proposta de uso de tecnologia para engajar alunos e aumentar a satisfação com o aprendizado não á uma ideia recente, ela nasceu junto com a revolução tecnológica e as últimas inovações e disseminação das tecnologias móveis ampliaram essas possibilidades e trouxeram novos desafios que precisam ser analisados e compreendidos pelas Academias de Polícias e demais instituições de formação e qualificação dos agentes operadores de Segurança Pública.

Os conteúdos gamificados têm como proposta envolver emocionalmente o indivíduo dentro de uma gama de tarefas a serem realizadas e, consequentemente, conhecimentos a serem apreendidos. Para isso se utiliza de mecanismos provenientes de jogos que são percebidos pelas pessoas como elementos prazerosos e desafiadores, favorecendo a criação de um ambiente propício ao engajamento do indivíduo. A Gamificação dos conteúdos possibilita a criação de ambientes que interajam positivamente com as emoções dos indivíduos e favoreçam o crescimento desses níveis de engajamento. 
A Gamificação pode promover a aprendizagem porque muitos de seus elementos são baseados em técnicas que os professores vêm usando há muito tempo; características como distribuir pontuações para atividades, apresentar feedback e encorajar a colaboração em projetos são as metas de muitos planos pedagógicos. A diferença é que a Gamificação promove uma camada mais explícita de interesse e um método para costurar esses elementos de forma a alcançar a similaridade com os games, o que resulta em uma linguagem na qual os indivíduos inseridos na cultura digital estão mais acostumados e, como resultado, conseguem alcançar essas metas de forma aparentemente mais eficiente e agradável. Com a mesma compreensão, mas apresentando um contraponto, os autores Cláudio Silva e Rafael Dubiela explanam:

A Gamificação de conteúdos como objetos de aprendizagem pode aumentar a motivação dos alunos ao incorporar elementos presentes nos games. No entanto, há o risco do objeto de aprendizagem não despertar nos alunos o desejo intrínseco de aprender pelo fato de ter sua dimensão de entretenimento como a única ou mais fortemente presente. Lidar com a motivação, particularmente em contexto educacional, requer uma abordagem que permita identificar e resolver problemas motivacionais específicos relacionados ao fato de como tornar o aprendizado intrinsicamente interessante, mantendo-o atrelado aos objetivos educacionais inicialmente definidos. (Silva \& Dubiela, 2014, p. 162)

A Gamificação surge como uma possibilidade de conectar a escola ao universo dos jovens com o foco na aprendizagem, utilizando elementos dos jogos para promover experiências que envolvem emocionalmente e cognitivamente os alunos, uma vez que a Gamificação pode explorar qualidades cognitivas, sociais, culturais e motivacionais do aluno; podendo auxiliar na motivação das pessoas fazendo com que estas percebam diretamente o impacto do seu aprendizado ou do treinamento a que estão sendo submetidas.

A utilização de elementos dos jogos contribui para o despertar de emoções pessoais através da vivência de uma experiência de forma intensificada; uma vez que o jogo possui forma de narrativa, onde são exploradas histórias de experiências, e essas experiências são fundamentais para constituir a memória, a comunicação e o próprio conhecimento dos indivíduos. Na mesma linha os autores Lynn Alves e colaboradores apresentam:

A Gamificação é a construção de modelos, sistemas ou modo de produção com foco nas pessoas, tendo como premissa a lógica dos games. Esses tipos de modelos levam em consideração a motivação, o sentimento e a participação das pessoas que estão envolvidas no processo. Um modelo de Gamificação se baseia na motivação, na capacidade de completar a ação e o que a 
desencadeia. Desta forma, considerando os elementos presentes na mecânica dos games, como por exemplo, o desafio, objetivos, níveis, sistema de feedback e recompensa (Salen \& Zimmerman, 2012; McGonigal, 2011) são criadas situações que mobilizam e engajam os sujeitos para a realização de determinadas ações. (Alves, Minho \& Diniz, 2014, p. 77)

Dessa forma a Gamificação se constitui na utilização da mecânica dos games em cenários não games, criando espaços de aprendizagem mediados pelo desafio, pelo prazer e entretenimento. Os autores citados (Alves, Minho \& Diniz, 2014 , p. 76) continuam sua explanação ao afirmarem que compreendem espaços de aprendizagem como distintos cenários escolares e não escolares que potencializam o desenvolvimento de habilidades cognitivas (planejamento, memória, atenção, entre outros), habilidades sociais (comunicação assertividade, resolução de conflitos interpessoais, entre outros) e habilidade motoras.

Por sua vez, Cláudio Silva e Rafael Dubiela esclarecem que os elementos citados, personagem, competição e regras do jogo, por definição podem ter efeito direto sobre o momento do aprendizado. Por exemplo, o personagem do jogo permite que os estudantes se identifiquem com o mesmo, enquanto a competição permite que os estudantes detenham o foco e a atenção. Assim, "as regras do jogo fazem com que o aluno se envolva em seu contexto ou no contexto de Gamificação" (Silva \& Dubiela, 2014, p. 148).

Outra contribuição da Gamificação dos conteúdos atribuído aos games é que eles eliminam completamente o medo de falhar, aumentando as chances de sucesso. O erro é parte natural do processo de interação e nenhum jogador com alguma experiência espera interagir com um game sem falhar várias vezes antes de atingir o sucesso. Dependendo da dificuldade e da disposição em superar um desafio, um jogador pode tentar inúmeras vezes e com inúmeras abordagens antes de obter sucesso, e isso é normal, faz parte do processo. Esse fator é importante na medida em que libera os indivíduos da pressão existente pela possibilidade de causar algum dano quando comete um erro ou falha. Como exemplo, aponta-se para os benefícios trazidos pelos simuladores de direção adotados por alguns Centros de Formação de Condutores que auxiliam os futuros motoristas na compreensão das complexas atividades necessárias a correta condução de veículos e motocicletas. Outros exemplos inquestionáveis da grande contribuição da Gamificação para a aquisição de variados e complexos conhecimentos são os simuladores de pilotagem de aviões e os estandes de tiro virtual, que há muito são empregados pelas Forças Armadas de um grande número de Países.

No Brasil, o crescimento exponencial de games consolida um fenômeno cultural que vem sendo investigado por diversas áreas acadêmica como a da educação, da comunicação, da psicologia, do design, da computação, entre ou- 
tras. A lógica presente nos games tem sido usada para área de marketing e processos de formação escolar e profissional. O próprio Ministério da Cultura já reconhece os games como um produto audiovisual, e o Ministério de Educação apoia o desenvolvimento de ambientes gamificados, a exemplo do Geekgames, uma plataforma online de aprendizado adaptativo que possibilita aos estudantes prepararem-se para o Exame Nacional para o Ensino Médio (Enem) através de um jogo virtual de questões; os alunos inscritos têm acesso a um diagnóstico e a um estudo personalizado que possibilita Identificar suas limitações e acompanhar os avanços nas áreas a serem avaliadas nas provas.

Por fim, apesar da Gamificação se apresentar como um fenômeno emergente com muitas potencialidades de aplicação em diversos campos da atividade humana, pois as linguagens, estratégias e pensamentos dos games são bastante populares, eficazes na resolução de problemas (pelo menos nos mundos virtuais) e aceitas naturalmente pelas atuais gerações que cresceram interagindo com esse tipo de entretenimento, sua integração no contexto de jogos digitais nas Academias de Polícia e demais instituições formadoras dependem do entendimento dos professores em como alinhar esse contexto com o assunto, os métodos instrucionais, as necessidades dos alunos e os objetivos de aprendizado, uma vez que essa integração só é possível se o professor tiver total conhecimento dos elementos de sua aula, bem como o conhecimento do jogo proposto para atuar no contexto do conteúdo.

\section{CONSIDERAÇÕES FINAIS}

O objetivo deste trabalho foi o de apresentar a Gamificação como uma metodologia ativa da aprendizagem apta a auxiliar as Academias de Polícia na aplicação de políticas públicas voltadas a divulgação e implementação da temática direitos humanos na formação e qualificação dos agentes operadores de Segurança Pública (policiais, bombeiros, guardas de trânsito, agentes penitenciários e demais servidores da Justiça e da Segurança Pública).

Para tanto, foram analisadas a estrutura didática e a proposta metodológica da Gamificação, explorando aspectos de sua mecânica e fatores motivacionais; apresentou-se uma síntese da conceituação do termo Gamificação, abordando tópicos sobre a importância do aspecto emocional no contexto educacional, além das características extraídas dos jogos na utilização de artefatos e ambientes que utilizam essa metodologia educacional. Verificou-se que Gamificação parte do conceito de estímulo ao pensamento sistemático como em um jogo, com o intuito de se resolver problemas, melhorar produtos, processos, objetos e ambientes com foco na motivação e no engajamento individual; processos que podem auxiliar os profissionais de Segurança Pública a perceberem questões fundamentais sobre 
direitos humanos que devem ser de seu conhecimento na missão de servir e proteger a comunidade, conhecendo o alcance e limite dos poderes conferidos pelo Estado.

Como resultado final da pesquisa e trabalho futuro, propõe-se implementar a metodologia da Gamificação como recurso didático na docência da temática direitos humanos pelas Academias de Polícia em experimento de sala de aula, analisando a aceitação dos alunos e mensurando os resultados de ganho ou perda na assimilação dos conteúdos frente a outros grupos de alunos que seguem a formação tradicional.

\section{REFERÊNCIAS}

Alves, Márcia Maria \& Teixeira, Oscar. (2014). Gamificação e objetos de aprendizagem (e-book), São Paulo: Editora Pimenta Café.

Alves, Lynn Rosalina Gama; Minho, Marcelle Rose da Silva; Diniz, Marcelo Vera Cruz. (2014). Gamificação: diálogos com a educação (e-book), São Paulo: Editora Pimenta Café.

Aveline, Paulo Vieira. (2009). Segurança pública como direito fundamental. Dissertação de Mestrado em Direito, Porto Alegre: Faculdade de Direito da PUC/RS.

Bicudo, Hélio Pereira. Direitos humanos e sua proteção. São Paulo: FTD, 1997.

Bobbio, Norberto. (2004). A era dos direitos. Trad. Carlos Nelson Coutinho. Rio de Janeiro: Elsevier.

Brasil. (2015). Constituição da República Federativa do Brasil 1988. Brasília: Câmara dos Deputados.

Brasil. (2012). Diretrizes Nacionais para a Educação em Direitos Humanos. Resolução CNE/ CP 1/2012. Brasília: Ministério da Educação - MEC.

Brasil. (2014). Matriz curricular nacional para ações formativas dos profissionais da área de segurança pública. Brasília: Senasp.

Brasil. (2000). Bases curriculares para a formação dos profissionais da área de segurança do cidadão. Brasília: Ministério da Justiça.

Brasil. (2013). Atuação policial na proteção dos direitos humanos de pessoas em situação de vulnerabilidade. Brasília: Ministério da Justiça, Secretaria Nacional de Segurança Pública.

Brasil. (2009). Plano Nacional de Educação em Direitos Humanos. Brasília: Secretaria Especial dos Direitos Humanos.

Brasil. (2006). Direitos humanos. Documentos internacionais. Brasília: Presidência da República, Secretaria Especial de Direitos Humanos.

Brasil. Declaração Universal dos Direitos Humanos de 10/12/1948. In: Documentos Internacionais. Brasília: Presidência da República, Secretaria Especial de Direitos Humanos. 
Carlos Pais, Luiz. (2010). Educação escolar e as tecnologias da informática. Belo Horizonte: Autêntica.

Culleton, Alfredo; Bragato, Fernanda Frizzo \& Fajardo, Sinara Porto. (2009). Curso de direitos humanos. São Leopoldo: Unisinos.

Douzinas, Costas. O fim dos direitos humanos. São Leopoldo: Unisinos, 2009.

Goldstein, Herman. (2003). Policiando uma sociedade livre. São Paulo: Edusp.

Gorczevski, Clovis. (2009). Direitos humanos, educação e cidadania: conhecer, educar, praticar. Santa Cruz do Sul: Edunisc.

Gomes, Heloisa Maria e Martins, Hiloko Ogihara. (2013). A ação docente na educação profissional. 2. ed. São Paulo: Senac.

Mariano, Benedito Domingos. (2002). Polícia: desafio da democracia brasileira. Porto Alegre: Corag.

Penteado Filho, Nestor Sampaio. (2006). Manual de direitos humanos. São Paulo: Saraiva, 2006.

Silva, Cláudio Henrique; Dubiela Rafael Pereira. (2014). Design motivacional no processo de gamificação de conteúdos para objetos de aprendizagem (e-book), São Paulo: Editora Pimenta Café. 
